\title{
Blueberry Phytochemicals Inhibit Growth and Metastatic Potential of MDA-MB-231 Breast Cancer Cells Through Modulation of the Phosphatidylinositol 3-Kinase Pathway
}

\author{
Lynn S. Adams ${ }^{1}$, Sheryl Phung ${ }^{1}$, Natalie Yee ${ }^{1}$, Navindra P. Seeram $^{2}$, Liya Li ${ }^{1}$, and Shiuan \\ Chen ${ }^{1, *}$ \\ ${ }^{1}$ Division of Tumor Cell Biology, Beckman Research Institute of the City of Hope, 1500 E. Duarte \\ Rd., Duarte, CA \\ 2Bioactive Botanical Research Laboratory, Department of Biomedical \& Pharmaceutical Sciences, \\ University of Rhode Island, 41 Lower College Road, Kingston, RI
}

\begin{abstract}
Dietary phytochemicals are known to exhibit a variety of anti-carcinogenic properties. This study investigated the chemopreventive activity of blueberry extract in triple negative breast cancer cell lines in vitro and in vivo. Blueberry decreased cell proliferation in HCC38, HCC1937 and MDAMB-231 cells with no effect on the non-tumorigenic MCF-10A cell line. Decreased metastatic potential of MDA-MB-231 cells by blueberry was shown through inhibition of cell motility using wound healing assays and migration through a PET membrane. Blueberry treatment decreased the activity of matrix metalloproteinase 9 and the secretion of urokinase-type plasminogen activator while increasing tissue inhibitor of metalloproteinase-1 and plasminogen activator inhibitor-1 secretion in MDA-MB-231 conditioned medium as shown by western blotting. Cell signaling pathways that control the expression/activation of these processes were investigated via western blotting and reporter gene assay. Treatment with blueberry decreased phosphatidylinositol 3-kinase (PI3K)/AKT and nuclear factor kappa-B (NFKB) activation in MDA-MB-231 cells where protein kinase $\mathrm{C}$ (PKC) and extracellular regulated kinase (ERK) were not affected. In vivo, the efficacy of blueberry to inhibit triple negative breast tumor growth was evaluated using the MDA-MB-231 xenograft model. Tumor weight and proliferation (Ki-67 expression) were decreased in blueberry treated mice, where apoptosis (caspase- 3 expression) was increased compared to controls. Immunohistochemical analysis of tumors from blueberry-fed mice showed decreased activation of AKT and p65 NFKB signaling proteins with no effect on the phosphorylation of ERK. These data illustrate the inhibitory effect of blueberry phytochemicals on the growth and metastatic potential of MDA-MB-231 cells through modulation of the PI3K/AKT/NFkB pathway.
\end{abstract}

\section{Keywords}

blueberry; phytochemicals; metastasis; triple negative; breast cancer

\section{Introduction}

The triple negative breast cancer phenotype, so named due to its lack of expression of estrogen receptor (ER), progesterone receptor (PR) and the HER-2 epidermal growth factor receptor (1), comprises $10-15 \%$ of all breast cancer cases (2). These breast cancers are characterized by 
an aggressive clinical history with poor disease-free and overall survival $(3,4)$ and show a high rate of metastasis to the cerebrum (5) and visceral sites compared to patients with other types of breast cancers. Currently, there is no defined, standard treatment strategy for prevention of reoccurrence for this disease other than traditional chemotherapy, to which it is highly resistant. Furthermore, there exists a limited amount of data on which to base treatment and prevention strategies, and no substantial information is available on targeted preventive measures for occurrence and reoccurrence of this disease.

Tumor metastasis is a multi-step process involving cell adhesion, degradation of the extracellular matrix (ECM) and cell migration. The metastatic potential of tumor cells is influenced by a balance of the expression of proteases and their inhibitory proteins. Matrix metalloproteases (MMPs) are a family of 24 secreted and membrane-type proteases which mediate this process. MMP-2 and MMP-9 are highly expressed in the uterus and breast and play an important role in the invasive stages of cancer (6). MMPs are directly activated by the serine protease plasmin, which is activated from its proenzyme form (plasminogen) by the serine protease uPA (urokinase-type plasminogen activator) (7). Overexpression of uPA has been found in many tumor types (8) and is correlated with poor prognosis (9). The expression of uPA is positively regulated by growth factors such as hepatocyte growth factor (HGF) and cell signaling pathways such as the PI3K/AKT pathway (10). Direct inhibition of uPA activity is modulated by plasminogen activator inhibitor (PAI), a secreted protein of the serpin family, and tissue inhibitors of metalloproteases (TIMPs) (11-13).

The motility and invasive potential of many metastatic cancer cell lines has been inhibited by phytochemicals such as [6]-gingerol (14), isothiocyanates from broccoli and watercress (15), tea catechins (16,17), genistein, apigenin (18), Ganoderma lucidum (19), ganoderic acid from the Ganoderma lucidum (20) mushroom and Phellinus linteus (21). Inhibition of MMP and uPA expression and activity was also shown in a number of these studies along with upregulation of the expression of TIMPs and PAI.

Bioactive substances in berries exhibit a variety of anti-cancer effects such as inhibition of cell proliferation, induction of apoptosis, modulation of cell signaling and effects on gene expression (22-24). Mulberry anthocyanins decreased MMP-2 and uPA and increased TIMP-2 and PAI expression in lung cancer cells (25). Flavonoid-enriched fractions from lowbush blueberries (Vaccinium angustifolium) downregulated the activity of MMP-2 and 9 and increased the activity of TIMP-1 and 2 in prostate cancer cells (26). In addition, black raspberries inhibited esophageal tumors in rats (27) and modulated NFאB, AP-1, nuclear factor of activated T cells (NFAT), and the expression of a number of genes associated with cellular matrix, cell signaling and apoptosis (28-30).

Preliminary data showed that of a panel of vegetable and fruit extracts, blueberry inhibited the proliferation of triple-negative breast cancer cell lines with no effect on the non-transformed MCF-10A cell line. This observation led us to postulate whether this activity extends to modulation of metastatic potential as well. In this study, effects on the motility and migration of cells along with the modulation of regulatory proteins MMP-2, MMP-9, uPA, TIMP and PAI in vitro were evaluated. The impact of daily oral administration of whole blueberry juice against tumor growth in mice was also evaluated. The results of these studies provide us with important information on the role of blueberry phytochemicals as preventive agents against the occurrence or reoccurrence (metastasis) of triple negative breast cancers. 


\section{Materials and Methods}

\section{Preparation of blueberry extract}

Whole, fresh lowbush blueberries (Vaccinium angustifolium) were weighed, juiced and the remaining solids separated by centrifugation $(4000 \mathrm{rpm}$ ) for 15 minutes. The volume was measured, sterile filtered using $0.3 \mu \mathrm{m}$ Millipore filters and frozen at $-20^{\circ} \mathrm{C}$ until use. Total phenolics were determined according to the Folin-Ciocalteau method (31) and measured as gallic acid equivalents (GAEs). Samples and phenolic standard (gallic acid) were processed identically. The absorbance was determined at $755 \mathrm{~nm}$ and final results calculated from the standard curve. Residual solvents (methanol, ethyl acetate, etc.) were removed from the extracts in vacuo by using a Buchi rotary evaporator. Dried extracts were reconstituted in vehicle (DMSO) for cell culture studies

\section{Cell Culture}

MDA-MB-231, HCC38, HCC1937 and MCF-10A cells were obtained from American Type Culture Collection (ATCC, Rockville, MD). MDA-MB-231, HCC38 and HCC1937 cells were cultured in RPMI-1640 containing 10\% fetal bovine serum in the presence of $100 \mathrm{U} / \mathrm{ml}$ penicillin and $0.1 \mathrm{~g} / \mathrm{L}$ streptomycin. MCF-10A cells were cultured in DMEM F-12 50/50 medium containing 5\% horse serum in the presence of $10 \mu \mathrm{g} / \mathrm{ml}$ insulin, $20 \mathrm{ng} / \mathrm{ml}$ epidermal growth factor, $100 \mathrm{ng} / \mathrm{ml}$ cholera toxin, $0.5 \mu \mathrm{g} / \mathrm{ml}$ hydrocortisone and $100 \mathrm{U} / \mathrm{ml}$ penicillin and $0.1 \mathrm{~g} / \mathrm{L}$ streptomycin. Cells were incubated at $37^{\circ} \mathrm{C}$ with $95 \%$ air and $5 \%$ carbon dioxide. All cells were used in experiments during the linear phase of growth.

\section{Cell Viability Assay}

Cells were treated with $100 \mu \mathrm{L}$ media plus water or blueberry extract and incubated for $72 \mathrm{~h}$. Extract was tested at $0,5,10,20,4080 \mu 1 / \mathrm{mL}$ concentrations. At the end of the drug exposure duration, cell viability was measured utilizing the CellTiter-Glo ${ }^{\circledR}$ Luminescent Cell Viability Assay according to manufacturer instructions (Technical Bulletin \# 288, Promega Corp., Madison, WI) as previously reported (22). All plates had control wells containing medium without cells to obtain a value for background luminescence which was subtracted from the test sample readings. Data are expressed as a ratio of treated to untreated cells, mean $\pm \mathrm{SE}$ for three replications.

\section{Apoptosis ELISA}

Cells were plated in $60 \mathrm{~mm}$ dishes at a density of 100,000 cells/dish and allowed to attach for 24 hours. Cells were treated with media+water control (blueberry extract is water soluble) or blueberry extract at a concentration of $12.5 \mu \mathrm{l} / \mathrm{mL}$ or $25 \mu 1 / \mathrm{mL}$ for 72 hours. Following treatments, non-adherent and adherent cells were collected and apoptosis was assessed utilizing the Cell Death Detection ELISA ${ }^{\text {PLUS }}$ Assay (Boehringer Mannheim, Indianapolis, IN) according to manufacturer instructions as previously reported (32). Background values were subtracted from readings (media plus reagent, no cells) and expressed as absorbance of dye bound to antibodies bound to mono and oligonucleosomes at $405 \mathrm{~nm}$ of each treated sample divided by media controls.

\section{Scratch Motility (Wound Healing) Assay}

MDA-MB-231 cells were plated in a 6-well plate at a concentration of $5 \times 10^{5}$ cells/well and allowed to form a confluent monolayer for 24 hours. Cells were then serum starved for 24 hours and the monolayer scratched with a pipette tip, washed with serum free medium (SFM) to remove floating cells and photographed (time 0 ). Cells were treated with either SFM or hepatocyte growth factor (HGF) $(40 \mathrm{ng} / \mathrm{ml})$ in the presence or absence of various 
concentrations of blueberry extract or Wortmannin $(0.2 \mu \mathrm{M})$, UO126 $(10 \mu \mathrm{M})$ or Bis-I (20 $\mu \mathrm{M})$ for 24 hours. Cells were then photographed again at 3 randomly selected sites per well.

\section{Migration Assay}

The migration assay was performed on a polyethylene terephthalate (PET) membrane ( $8 \mu \mathrm{m}$ pore size) in a Tissue Culture (TC) insert (Beckton Dickinson, Franklin Lakes, NJ). MDAMB-231 cells were plated into the upper chamber of the TC insert containing SFM, and the insert placed into a well of a 6 -well plate containing $2 \mathrm{ml}$ of either $\mathrm{SFM}+\mathrm{HGF}(40 \mathrm{ng} / \mathrm{ml})$ alone or SFM+HGF with either wortmannin $(0.2 \mu \mathrm{M})$, UO126 $(10 \mu \mathrm{M})$ or Bis-I $(20 \mu \mathrm{M})$ or various concentrations of blueberry extract. The control well contained SFM only. After 24 hours, the top surface of the TC insert was scraped using a cotton swab and the cells on the lower surface of the membrane were fixed for 15 minutes with methanol and stained with crystal violet. Cells which had migrated to the bottom of the membrane were visualized and counted using an inverted microscope. For each replicate $(\mathrm{n}=3)$ cells in four randomly selected fields were counted and averaged. Data is expressed as a ratio to the HGF-treated group.

\section{Western Blotting}

MDA-MB-231 cells were serum starved for 24 hours and then treated with either vehicle control, appropriate cell signaling inhibitors or various concentrations of blueberry extract for 2 hours prior to stimulation with HGF $(40 \mathrm{ng} / \mathrm{ml})$ for 15 minutes. Cell lysates were run on a $10 \%$ acrylamide gel, transferred to a nitrocellulose membrane and probed with either antiphospho and total AKT, ERK antibodies or phospho PKC plus $\beta$-actin (Cell Signaling Technology, Inc., Beverly, MA). Bands were visualized via chemiluminescence using HRPconjugated secondary antibodies. Bands were quantified using Biorad Quantity One software.

\section{Animal Experiments}

Five-week old, intact female BALB/c Nu-Nu, athymic mice were purchased (Charles River Laboratories) and randomly divided into two groups of 8 mice each. At 6 weeks of age, mice were gavage fed with either $100 \mu \mathrm{l}$ water control or $100 \mu \mathrm{l}$ blueberry. Animals were gavaged daily for the duration of the experiment. At 7 weeks of age, mice were injected subcutaneously with MDA-MB-231 cells $\left(3 \times 10^{6}\right)$ in Matrigel (BD Biosciences, San Jose, CA). Body weights were monitored weekly as an indicator of overall health. At the end of 7 weeks of gavage treatment, mice were euthanized via $\mathrm{CO}_{2}$ asphyxiation; tumors were removed, weighed, and sent for hematoxilin and eosin (H\&E) histological staining through the City of Hope Pathology Department Core Facility. Tumor specimens were stained using cleaved caspase-3 antibody (Cell Signaling Technology, Danvers, MA) for apoptosis and Ki-67 antibody (Dakocytomation, Carpinteria, CA) staining for cell proliferation, and phospho-ERK, AKT and p65 NFKB (Cell Signaling Technology, Danvers, MA). Immunohistochemistry slides were quantified by taking six random fields and counting stained and unstained cells and dividing each by the total number of cells counted to generate the percent of positive cells. The protocol for this study was approved by the City of Hope Research Animal Care Committee.

\section{Zymogram Analysis of MMP Activity}

MDA-MB-231 cells were treated with serum free medium for 24 hours prior to treatment with HGF $(40 \mathrm{ng} / \mathrm{ml})$ or HGF plus either wortmannin $(0.2 \mu \mathrm{M})$ or various concentrations of blueberry extract. Cells were incubated for 24 hours, the medium collected and concentrated using Microcon YM-10 filters (Millipore, Billerica, MA). Concentrated medium was mixed with electrophoresis buffer without reducing agent, incubated at RT for 15 minutes and loaded on 10\% acrylamide gels containing gelatin (Biorad, Hercules, CA). Gels were run at $120 \mathrm{~V}$ for 90 minutes, and incubated in renaturing solution (Biorad, Hercules, CA) for 30 minutes at RT with agitation. Gels were rinsed once in water and incubated in developing buffer (Biorad, 
Hercules, CA) for 30 minutes at RT with agitation before incubation in fresh developing buffer at $37^{\circ} \mathrm{C}$ overnight. Developing buffer was decanted, the gels stained with $0.3 \%$ coomassie blue solution for 1 hour and destained until clear bands were visible. Bands were visualized on a Kodak Gel Logic 200 imaging system with the Kodak 1D software. Loading control included equal amounts of sample run on $10 \%$ acrylamide gels and stained with coomassie blue.

\section{UPA, PAI and Timp-1 Secretion}

Conditioned medium (see above) was also evaluated for secretion of uPA, PAI and Timp-1 via western blot analysis with anti-uPA, PAI and Timp-1 antibodies (Santa Cruz Biotechnology, Santa Cruz, CA).

\section{Statistical Analysis}

To assess statistical significance, values were compared to controls with either Student's $t$ - test or one-way ANOVA, followed by Dunnett's Multiple Range test $(\alpha=0.05)$ using Prism GraphPad 4 software (GraphPad Software, inc).

\section{Results}

\section{Polyphenol content of blueberry extract and isolated fractions}

Water, methanol $(\mathrm{MeOH})$ and ethyl acetate (EA) fractions of the original blueberry extract were created. Total polyphenol content of blueberry extract and the fractions was determined using the Folin-Ciocalteau method and expressed as gallic acid equivalents. Results showed that whole blueberry extract contained $1.59 \%$ polyphenols, EA contained $7.16 \%, \mathrm{MeOH}$ contained $1.45 \%$ and water extract contained no detectable polyphenolic compounds (based on dry matter). Therefore, polyphenolic compounds were more highly concentrated in the EA fraction compared to whole blueberry or the $\mathrm{MeOH}$ and water fractions.

\section{Antiproliferative effects of blueberry extracts}

Blueberry extract was tested in triple negative breast cancer cell lines (MDA-MB-231, HCC38 and HCC1937) and one untransformed breast cell line (MCF-10A). The $\mathrm{pH}$ of medium plus blueberry extract was tested at each concentration and $\mathrm{pH}$ was not allowed to go below 7.0. Results showed blueberry was most effective in the most aggressive cell line (MDA-MB-231) while having no significant effect on the untransformed MCF-10A cells (Figure 1A).

Water, $\mathrm{MeOH}$ and EA fractions of the blueberry extract were also tested against the proliferation of MDA-MD-231 cells in increasing concentrations. Results showed that the activity of the fractions was lower in comparison to the whole blueberry extract, despite the increased polyphenolic content of the EA fraction. Two-by-two and a combination of all three fractions did not improve the activity (Figure 1B). Therefore, we may conclude that whole blueberry was more active than its isolated fractions. However, it is also possible that the active components may get destroyed or lost during the fractionation process. Further development of methods to more efficiently recover individual fractions is needed.

\section{Induction of apoptosis by blueberry extract}

To determine whether the decreased cell number was due to the induction of cell death, apoptosis was quantitated using the Cell Death Detection ELISA ${ }^{\text {PLUS }}$ assay (Roche Diagnostics, Mannheim, Germany). Following treatment with blueberry extract (12.5 and 25 $\mu \mathrm{L} / \mathrm{mL}$ ) for 72 hours, a 1.5-fold increase in DNA fragmentation was detected compared to water treated control cells. This small amount of apoptosis in the blueberry-treated cells does not account for the observed decrease seen in the cell viability assay. Therefore, the results of the viability assay can largely be attributed to an inhibition of proliferation. 


\section{Effects of blueberry extract on the metastatic potential of MDA-MB-231 cells}

Due to the highly invasive nature of triple negative breast cancers, we investigated the effects of blueberry extract on the invasive potential of MDA-MB-231 cells in vitro. Wound healing assays were utilized to determine whether blueberry extract could inhibit HGF-induced migration of MDA-MB-231 cells. Twenty-four hours after cell monolayers were wounded, HGF treated cells had completely filled in the cleared area. Treatment with 20 and $30 \mu \mathrm{l} / \mathrm{ml}$ of blueberry extract inhibited HGF-induced migration of cells (Figure 2A). To determine the importance of the signaling pathways PI3K/AKT, ERK and PKC in the migration of MDAMB-231 cells, the cell signaling inhibitors wortmannin, UO126 and Bis-I were utilized. Treatment with all three inhibitors also inhibited the migration of cells in this assay (Figure $2 \mathrm{~B}$ ), showing the involvement of these signaling pathways in the migration of triple negative breast cancer cells.

Inhibition of HGF-induced migration by blueberry was investigated using the PET membrane method. MDA-MB-231 cells treated with HGF alone migrated to the bottom side of the membrane. Blueberry extract ( 20 or $30 \mu \mathrm{l} / \mathrm{ml}$ ) significantly reduced cell migration (Figure $2 \mathrm{C}$ ) as did treatment with wortmannin, UO126 or Bis-I (Figure 2D).

\section{Inhibition of cell signaling pathways by blueberry in vitro}

Due to the importance of the PI3K/AKT, ERK and PKC signaling pathways to the activation of MMP's, we determined the effect of blueberry extract on the activation of these pathways. Results revealed that AKT was phosphorylated in response to HGF treatment, however pretreatment with blueberry extract at 10,20 and $30 \mu \mathrm{l} / \mathrm{ml}$ significantly reduced HGF-induced AKT activation $(\mathrm{P} \leq 0.05,0.01)$ (Figure $3 \mathrm{~A})$. Blueberry also decreased HGF-induced transcriptional activity of NFKB at $20 \mu \mathrm{l} / \mathrm{ml}(\mathrm{p} \leq 0.05)$ and $30 \mu \mathrm{l} / \mathrm{ml}(\mathrm{p} \leq 0.01)$ (Figure 3D). Alternatively, the phosphorylation of ERK and PKC were unaffected (Figure 3B \& C). Although inhibition of ERK and PKC decreased cell motility and migration in our assays, blueberry does not affect migration through inhibition of these pathways. On the other hand, inhibition of PI3K/AKT leading to downregulation of NFKB transcriptional activity may be one mechanism behind the action of blueberry extract against MDA-MB-231 cell migration.

\section{Inhibition of MMP activity and the secretion of its regulatory proteins}

The activity of blueberry extract against gelatinase (MMP-2 and 9) activity was assayed using gelatin zymogram gels. Zymography identifies MMPs based on their preferential substrate (gelatin in the case of MMP-2 and 9) and molecular weight. Once the sample is separated on the gel, it is incubated in an activation buffer and the MMPs present in the sample digest the substrate present in the gel, showing the activity of the enzymes. When the gel is stained, activity is shown as a cleared region (or a clear band) in the gel.

In conditioned medium from cells treated with $\mathrm{HGF}$, a band was identified at $92 \mathrm{kDa}$ (corresponding to MMP-9). Treatment with blueberry $(30 \mu \mathrm{l} / \mathrm{mL})$ extract or wortmannin decreased the intensity the band, indicating inhibition of MMP-9 activity (Figure 4A). This suggests that the inhibitory activity of blueberry on the migration of MDA-MB-231 cells may be due to inhibition of MMP-9 activity, and that inhibition of the PI3K/AKT signaling pathway is also important to MMP-9 activation in this cell line. The activity of other MMP family members was also investigated using casein gels. Casein is the preferential substrate for the detection of MMP-11, 1, 7, 12, 13 and 9. No cleared zones (or bands) were seen in this assay, suggesting a lack of activity of these MMPs in the MDA-MB-231 cells (data not shown).

The secretion of the MMP inhibitors UPA, TIMP-1 and PAI-1 in conditioned medium from MDA-MB-231 cells was also evaluated as this is one possible mechanism of blueberry-induced inhibition of MMP activity. Western blot analysis revealed that HGF increased and blueberry 
extract decreased secretion of uPA in conditioned medium (Figure 4B). A trend for increased Timp-1 expression was observed in blueberry and wortmannin-treated cells compared to HGFtreated cells, although this was not statistically significant when quantified (Figure 4C). In addition, PAI expression was significantly increased in blueberry-treated cells (Figure 4D).

\section{In vivo chemopreventive effects of blueberry extract}

To evaluate the chemopreventive potential of the blueberry extract in vivo, we utilized the MDA-MB-231 xenograft model. Blueberry treatment was initiated one week prior to and continued six weeks following tumor cell injection. Results showed significantly smaller tumor weights in the mice treated with blueberry extract verses control mice $(\mathrm{p} \leq 0.01)$ (Figure 5A). Consistent with the in vitro experiments, proliferation (Ki-67 staining) of tumor specimens was significantly decreased in blueberry treated mice $(\mathrm{p} \leq 0.01)$ (Figure $5 \mathrm{~B})$ and apoptosis (caspase 3 staining) of tumor specimens was significantly increased $(\mathrm{p} \leq 0.01)$ (Figure 5C). These results illustrate that blueberry juice is orally active and that the intake of blueberry may have an inhibitory effect on estrogen and HER-2-independent tumor growth in vivo.

Tumor specimens from the blueberry-treated and water-treated mice were stained via immunohistochemistry for active (phospho) AKT, ERK and the p65 subunit of NFkB. The activation of $\mathrm{NFKB}$ and $\mathrm{AKT}$ has been identified as important to triple negative breast cancer growth and metastasis; as has the ERK pathway. Results showed that both p65 NFKB and AKT phosphorylation were significantly reduced in tumors from blueberry-treated mice $(p \leq 0.01)$ (Figure 6A \& B). Alternatively, there was no significant difference in the amount of phosphoERK staining between untreated and treated tumor specimens (Figure 6C), which is consistent with our in vitro experiments.

\section{Discussion}

The aims of this study were to determine the anti-tumor activity of a whole blueberry preparation against MDA-MB-231 cells in a xenograft mouse model and to investigate the modulation of the metastatic process in vitro. Preliminary results showed that among a panel of whole food preparations, blueberry exhibited the highest antiproliferative effect against MDA-MB-231 cells while having no effect on the non-transformed MCF-10A cell line. One aim in developing chemopreventive agents is to identify those that are easily accessible and non-toxic, therefore, blueberry was chosen for further study.

The failure of the isolated blueberry fractions to equal or exceed the antiproliferative activity of the whole blueberry extract is similar to results seen with the fractionation of cranberry juice. In that study, whole cranberry juice had higher antiproliferative activity than isolated anthocyanin and proanthocyanidins fractions (33). Because the isolated compounds from blueberry and cranberry are phenolic in nature, they are prone to oxidation/decomposition when purified and taken out of the matrix of the whole fruit/juice. Therefore, we conclude that the isolated fractions are less active than whole blueberry due to their separation from the whole, and whole blueberry extract was utilized for further investigations.

In vivo experiments showed no adverse effects of blueberry when ingested by mice. In addition, oral activity was observed through decreased growth of MDA-MB-231-derived tumors in a xenograft mouse model. The decreased tumor size was attributed to decreased cell proliferation and increased apoptosis, as measured by Ki-67 and caspase- 3 immunohistochemical staining of tumor tissues. A recent study by Aiyer et al. showed comparable results in rats, where oral administration of whole blueberry powder decreased breast tumor volume by $40 \%$ compared to untreated control animals (34). Similar studies showed that oral ingestion of blueberry extract decreased hemangioendothelioma tumor size in mice (35). In contrast, studies by Stoner et al. showed that diets containing 5 and $10 \%$ of whole blueberry powder did not inhibit N- 
nitrosomethylbenzylamine-induced esophageal tumors in rats (36). The differing inhibitory effects on breast and esophageal tumor growth observed in these two studies are likely due to the different tumor models used. Overall, studies suggest that the oral intake of blueberries may convey chemopreventive benefits in vivo.

Inhibition of invasive potential is important to the prevention of tumor reoccurrence. In vitro experiments demonstrated that treatment with blueberry extract inhibited HGF-induced migration of MDA-MB-231 cells and decreased MMP-9 activity. A large number of natural products, including berries, have been shown to inhibit metastatic potential in cancer cell lines including prostate, lung, breast and fibrosarcoma. These products were found to target key proteins including MMP-2 and 9, uPA and the MMP inhibitors TIMP-1 and PAI. In addition, the AKT, NFאB, AP-1, JNK and ERK signaling pathways were also regulated in a number of these studies, illustrating the importance of these signaling pathways. $(18,25,26,37-41)$. The secretion of metastasis-related proteins has been shown to be, at least in part, under the control of the above-mentioned cell signaling pathways, although their involvement can vary by tissue/ cell type. For example, our in vitro experiments showed that blueberry treatment of MDAMB-231 cells had no effect on the activation of PKC and ERK, where it inhibited the activation of the PI3K/AKT/NFאB pathway. Therefore, in further studies on the effects of blueberry on metastasis related proteins, we focused on the role of this pathway.

In our experiments with blueberry, the modulation of metastatic proteins was shown to be through a decrease in UPA secretion and increased secretion of the MMP inhibitor PAI, the expression of which can be controlled by the PI3K/AKT/NFKB pathway. These cell signaling proteins are also important to the proliferation and survival of tumor cells $(42,43)$. Therefore, one mechanism by which blueberry may alter tumor growth and metastatic potential of MDAMB-231 cells is through modulation of the PI3K/AKT/NFאB pathway. In contrast, Huang et al. reported that a methanol fraction of blueberry failed to inhibit UVB-induced activation of NFאB and AP-1 in mouse epidermal cells (30). The authors speculated that these observations may be due to the different anthocyanin profile of blueberries as compared to other berries. The Huang study induced skin carcinogenesis in mice via exposure to UV radiation. In addition, the authors treated the mice with a methanol fraction of blueberry. Therefore, the different cancer type, route of induction and blueberry treatment (our study utilized blueberry juice which contains both water and lipid-soluble compounds that could work synergistically to inhibit NFKB activity) likely accounts for the differing inhibitory effect of blueberry on NFkB between the Huang study and ours.

The results of our studies suggest that the oral intake of blueberries could be a key component of long-term breast cancer prevention strategies. We showed not only that blueberry ingestion in mice decreased tumor growth but also the activity of AKT and NFKB, which are markers for metastatic potential in breast tumors. Several studies of tissues from breast cancer patients have shown that the activity of PI3K and AKT are significantly increased in the triple-negative subset of breast cancers (44-46). This illustrates the importance of these signaling pathways to the pathology of this disease.

A limitation of this study is that in vitro studies cannot be extrapolated to possible activity in vivo. The role of in vitro studies is to screen for activity against biomarkers that can then be tested in vivo using animal studies. Our intent with the in vitro studies was to evaluate mechanisms through which blueberry may modulate the metastatic potential of MDA-MB-231 cells, which are now under investigation in vivo.

It was suggested that the antiproliferative activity of fruit extracts against cancer cell lines is due to the production of hydrogen peroxide $\left(\mathrm{H}_{2} \mathrm{O}_{2}\right)$ and resultant oxidative stress (47). However, Liu et al showed that $\mathrm{H}_{2} \mathrm{O}_{2}$ was not produced after addition of apple extracts to 
medium, there is no correlation between phenolic content and antiproliferative activity, and suggested that the previous results were due to incorrect measurement methods (48). Therefore, the results of our proliferation studies are likely a consequence of the effects of the phytochemicals in blueberries, not the production of $\mathrm{H}_{2} \mathrm{O}_{2}$ in the cell medium.

The dose of blueberry in our in vivo study is equal to a fresh blueberry intake of $25 \mathrm{grams} / \mathrm{kg}$. With a conversion to human dose (based on surface area) (49), this is equal to $2.03 \mathrm{~g} / \mathrm{kg}$ human or 122 grams $(4.3 \mathrm{oz})$ of fresh blueberries/day for a $60 \mathrm{~kg}$ person. A single serving of fresh blueberries is $6 \mathrm{oz}$. which is an attainable intake for the average person. Therefore, blueberry intake could be an important part of dietary cancer prevention strategies.

\section{Acknowledgments}

Financial support: City of Hope CAM Research Grant Program and National Institutes of Health Grant ES08258 (Shiuan Chen)

\section{Literature Cited}

1. Reis-Filho JS, Tutt AN. Triple negative tumours: a critical review. Histopathology 2008;52:108-18. [PubMed: 18171422]

2. Cleator S, Heller W, Coombes RC. Triple-negative breast cancer: therapeutic options. The lancet oncology 2007;8:235-44. [PubMed: 17329194]

3. van de Rijn M, Perou CM, Tibshirani R, et al. Expression of cytokeratins 17 and 5 identifies a group of breast carcinomas with poor clinical outcome. The American journal of pathology 2002;161:19916. [PubMed: 12466114]

4. Foulkes WD, Brunet JS, Stefansson IM, et al. The prognostic implication of the basal-like (cyclin E high/p27 low/p53+/glomeruloid-microvascular-proliferation+) phenotype of BRCA1-related breast cancer. Cancer research 2004;64:830-5. [PubMed: 14871808]

5. Tsuda H, Takarabe T, Hasegawa F, Fukutomi T, Hirohashi S. Large, central acellular zones indicating myoepithelial tumor differentiation in high-grade invasive ductal carcinomas as markers of predisposition to lung and brain metastases. The American journal of surgical pathology 2000;24:197202. [PubMed: 10680887]

6. Folgueras AR, Pendas AM, Sanchez LM, Lopez-Otin C. Matrix metalloproteinases in cancer: from new functions to improved inhibition strategies. The International journal of developmental biology 2004;48:411-24. [PubMed: 15349816]

7. Sliva D, English D, Lyons D, Lloyd FP Jr. Protein kinase C induces motility of breast cancers by upregulating secretion of urokinase-type plasminogen activator through activation of AP-1 and NFkappaB. Biochemical and biophysical research communications 2002;290:552-7. [PubMed: 11779207]

8. Markus G. The relevance of plasminogen activators to neoplastic growth. A review of recent literature. Enzyme 1988;40:158-72. [PubMed: 3049065]

9. Look M, van Putten W, Duffy M, et al. Pooled analysis of prognostic impact of uPA and PAI-1 in breast cancer patients. Thrombosis and haemostasis 2003;90:538-48. [PubMed: 12958624]

10. Aguirre Ghiso JA, Alonso DF, Farias EF, Gomez DE, de Kier Joffe EB. Deregulation of the signaling pathways controlling urokinase production. Its relationship with the invasive phenotype. European journal of biochemistry / FEBS 1999;263:295-304. [PubMed: 10406935]

11. Chazaud B, Ricoux R, Christov C, Plonquet A, Gherardi RK, Barlovatz-Meimon G. Promigratory effect of plasminogen activator inhibitor- 1 on invasive breast cancer cell populations. The American journal of pathology 2002;160:237-46. [PubMed: 11786417]

12. Lijnen HR. Pleiotropic functions of plasminogen activator inhibitor-1. J Thromb Haemost 2005;3:3545. [PubMed: 15634264]

13. Stetler-Stevenson WG. Tissue inhibitors of metalloproteinases in cell signaling: metalloproteinaseindependent biological activities. Science signaling 2008;1:re6. [PubMed: 18612141] 
14. Lee HS, Seo EY, Kang NE, Kim WK. [6]-Gingerol inhibits metastasis of MDA-MB-231 human breast cancer cells. The Journal of nutritional biochemistry 2008;19:313-9. [PubMed: 17683926]

15. Rose P, Huang Q, Ong CN, Whiteman M. Broccoli and watercress suppress matrix metalloproteinase-9 activity and invasiveness of human MDA-MB-231 breast cancer cells. Toxicology and applied pharmacology 2005;209:105-13. [PubMed: 15953625]

16. Ho YC, Yang SF, Peng CY, Chou MY, Chang YC. Epigallocatechin-3-gallate inhibits the invasion of human oral cancer cells and decreases the productions of matrix metalloproteinases and urokinaseplasminogen activator. J Oral Pathol Med 2007;36:588-93. [PubMed: 17944751]

17. Bigelow RL, Cardelli JA. The green tea catechins, (-)-Epigallocatechin-3-gallate (EGCG) and (-)Epicatechin-3-gallate (ECG), inhibit HGF/Met signaling in immortalized and tumorigenic breast epithelial cells. Oncogene 2006;25:1922-30. [PubMed: 16449979]

18. Lee WJ, Chen WK, Wang CJ, Lin WL, Tseng TH. Apigenin inhibits HGF-promoted invasive growth and metastasis involving blocking PI3K/Akt pathway and beta 4 integrin function in MDA-MB-231 breast cancer cells. Toxicology and applied pharmacology 2008;226:178-91. [PubMed: 17961621]

19. Sliva D, Labarrere C, Slivova V, Sedlak M, Lloyd FP Jr, Ho NW. Ganoderma lucidum suppresses motility of highly invasive breast and prostate cancer cells. Biochemical and biophysical research communications 2002;298:603-12. [PubMed: 12408995]

20. Jiang J, Grieb B, Thyagarajan A, Sliva D. Ganoderic acids suppress growth and invasive behavior of breast cancer cells by modulating AP-1 and NF-kappaB signaling. International journal of molecular medicine 2008;21:577-84. [PubMed: 18425349]

21. Sliva D, Jedinak A, Kawasaki J, Harvey K, Slivova V. Phellinus linteus suppresses growth, angiogenesis and invasive behaviour of breast cancer cells through the inhibition of AKT signalling. British journal of cancer 2008;98:1348-56. [PubMed: 18362935]

22. Seeram NP, Adams LS, Zhang Y, et al. Blackberry, black raspberry, blueberry, cranberry, red raspberry, and strawberry extracts inhibit growth and stimulate apoptosis of human cancer cells in vitro. Journal of agricultural and food chemistry 2006;54:9329-39. [PubMed: 17147415]

23. Seeram, NP.; Heber, D. Impact of berry phytochemicals on human health: Effects beyond antioxidation. In: Ho, CT.; Shahidi, FS., editors. Lipid Oxidation and Antioxidants: Chemistry, Methodologies and Health Effects. Oxford: Oxford Press; 2006.

24. Seeram NP. Berry fruits: compositional elements, biochemical activities, and the impact of their intake on human health, performance, and disease. Journal of agricultural and food chemistry 2008;56:6279. [PubMed: 18211023]

25. Chen PN, Chu SC, Chiou HL, Kuo WH, Chiang CL, Hsieh YS. Mulberry anthocyanins, cyanidin 3rutinoside and cyanidin 3-glucoside, exhibited an inhibitory effect on the migration and invasion of a human lung cancer cell line. Cancer letters 2006;235:248-59. [PubMed: 15975709]

26. Matchett MD, MacKinnon SL, Sweeney MI, Gottschall-Pass KT, Hurta RA. Inhibition of matrix metalloproteinase activity in DU145 human prostate cancer cells by flavonoids from lowbush blueberry (Vaccinium angustifolium): possible roles for protein kinase $\mathrm{C}$ and mitogen-activated protein-kinase-mediated events. The Journal of nutritional biochemistry 2006;17:117-25. [PubMed: 16111875]

27. Wang LS, Hecht SS, Carmella SG, et al. Anthocyanins in black raspberries prevent esophageal tumors in rats. Cancer prevention research (Philadelphia, Pa 2009;2:84-93.

28. Lechner JF, Reen RK, Dombkowski AA, et al. Effects of a black raspberry diet on gene expression in the rat esophagus. Nutrition and cancer 2008;60:61-9. [PubMed: 19003582]

29. Li J, Zhang D, Stoner GD, Huang C. Differential effects of black raspberry and strawberry extracts on BaPDE-induced activation of transcription factors and their target genes. Molecular carcinogenesis 2008;47:286-94. [PubMed: 18085529]

30. Huang C, Zhang D, Li J, Tong Q, Stoner GD. Differential inhibition of UV-induced activation of NF kappa B and AP-1 by extracts from black raspberries, strawberries, and blueberries. Nutrition and cancer 2007;58:205-12. [PubMed: 17640167]

31. Sharma M, Li L, Celver J, Killian C, Kovoor A, Seeram NP. Effects of Fruit Ellagitannin Extracts, Ellagic Acid, and Their Colonic Metabolite, Urolithin A, on Wnt Signaling (dagger). Journal of agricultural and food chemistry. 2009 
32. Adams LS, Phung S, Wu X, Ki L, Chen S. White button mushroom (Agaricus bisporus) exhibits antiproliferative and proapoptotic properties and inhibits prostate tumor growth in athymic mice. Nutrition and cancer 2008;60:744-56. [PubMed: 19005974]

33. Seeram NP, Adams LS, Hardy ML, Heber D. Total cranberry extract versus its phytochemical constituents: antiproliferative and synergistic effects against human tumor cell lines. Journal of agricultural and food chemistry 2004;52:2512-7. [PubMed: 15113149]

34. Aiyer HS, Srinivasan C, Gupta RC. Dietary berries and ellagic acid diminish estrogen-mediated mammary tumorigenesis in ACI rats. Nutrition and cancer 2008;60:227-34. [PubMed: 18444155]

35. Gordillo G, Fang H, Khanna S, Harper J, Phillips G, Sen CK. Oral administration of blueberry inhibits angiogenic tumor growth and enhances survival of mice with endothelial cell neoplasm. Antioxidants \& redox signaling 2009;11:47-58. [PubMed: 18817478]

36. Stoner GD. Foodstuffs for preventing cancer: the preclinical and clinical development of berries. Cancer prevention research (Philadelphia, Pa 2009;2:187-94.

37. Azios NG, Dharmawardhane SF. Resveratrol and estradiol exert disparate effects on cell migration, cell surface actin structures, and focal adhesion assembly in MDA-MB-231 human breast cancer cells. Neoplasia (New York, NY 2005;7:128-40.

38. Kong D, Li Y, Wang Z, Banerjee S, Sarkar FH. Inhibition of angiogenesis and invasion by 3,3'diindolylmethane is mediated by the nuclear factor-kappaB downstream target genes MMP-9 and uPA that regulated bioavailability of vascular endothelial growth factor in prostate cancer. Cancer research 2007;67:3310-9. [PubMed: 17409440]

39. Hung SH, Shen KH, Wu CH, Liu CL, Shih YW. Alpha-mangostin suppresses PC-3 human prostate carcinoma cell metastasis by inhibiting matrix metalloproteinase-2/9 and urokinase-plasminogen expression through the JNK signaling pathway. Journal of agricultural and food chemistry 2009;57:1291-8. [PubMed: 19178296]

40. Kwon GT, Cho HJ, Chung WY, Park KK, Moon A, Park JH. Isoliquiritigenin inhibits migration and invasion of prostate cancer cells: possible mediation by decreased JNK/AP-1 signaling. The Journal of nutritional biochemistry 2009;20:663-76. [PubMed: 18824345]

41. Yoon SO, Shin S, Lee HJ, Chun HK, Chung AS. Isoginkgetin inhibits tumor cell invasion by regulating phosphatidylinositol 3-kinase/Akt-dependent matrix metalloproteinase-9 expression. Molecular cancer therapeutics 2006;5:2666-75. [PubMed: 17121913]

42. Dannemann N, Hart JR, Ueno L, Vogt PK. Phosphatidylinositol 4,5-bisphosphate (PIP(2))-specific AKT1 is oncogenic. International journal of cancer. 2009

43. Yamaguchi N, Ito T, Azuma S, et al. Constitutive activation of nuclear factor-kappaB is preferentially involved in the proliferation of basal-like subtype breast cancer cell lines. Cancer science 2009;100:1668-74. [PubMed: 19538528]

44. Schneider BP, Winer EP, Foulkes WD, et al. Triple-negative breast cancer: risk factors to potential targets. Clin Cancer Res 2008;14:8010-8. [PubMed: 19088017]

45. Umemura S, Yoshida S, Ohta Y, Naito K, Osamura RY, Tokuda Y. Increased phosphorylation of Akt in triple-negative breast cancers. Cancer science 2007;98:1889-92. [PubMed: 17892507]

46. Aleskandarany MA, Rakha EA, Ahmed MA, et al. PIK3CA expression in invasive breast cancer: a biomarker of poor prognosis. Breast cancer research and treatment. 2009

47. Lapidot T, Walker MD, Kanner J. Can apple antioxidants inhibit tumor cell proliferation? Generation of $\mathrm{H}(2) \mathrm{O}(2)$ during interaction of phenolic compounds with cell culture media. Journal of agricultural and food chemistry 2002;50:3156-60. [PubMed: 12009979]

48. Liu RH, Sun J. Antiproliferative activity of apples is not due to phenolic-induced hydrogen peroxide formation. Journal of agricultural and food chemistry 2003;51:1718-23. [PubMed: 12617611]

49. Reagan-Shaw S, Nihal M, Ahmad N. Dose translation from animal to human studies revisited. Faseb J 2008;22:659-61. [PubMed: 17942826] 
A

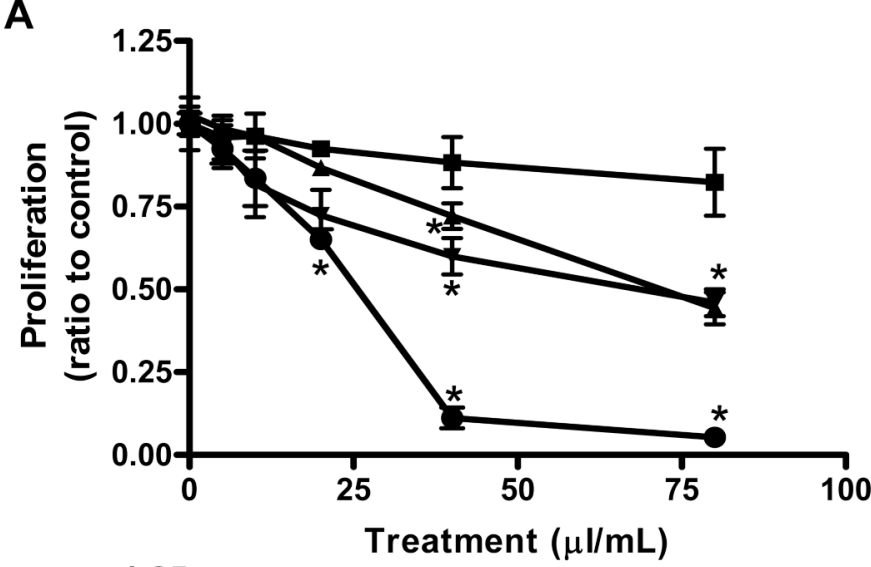

B

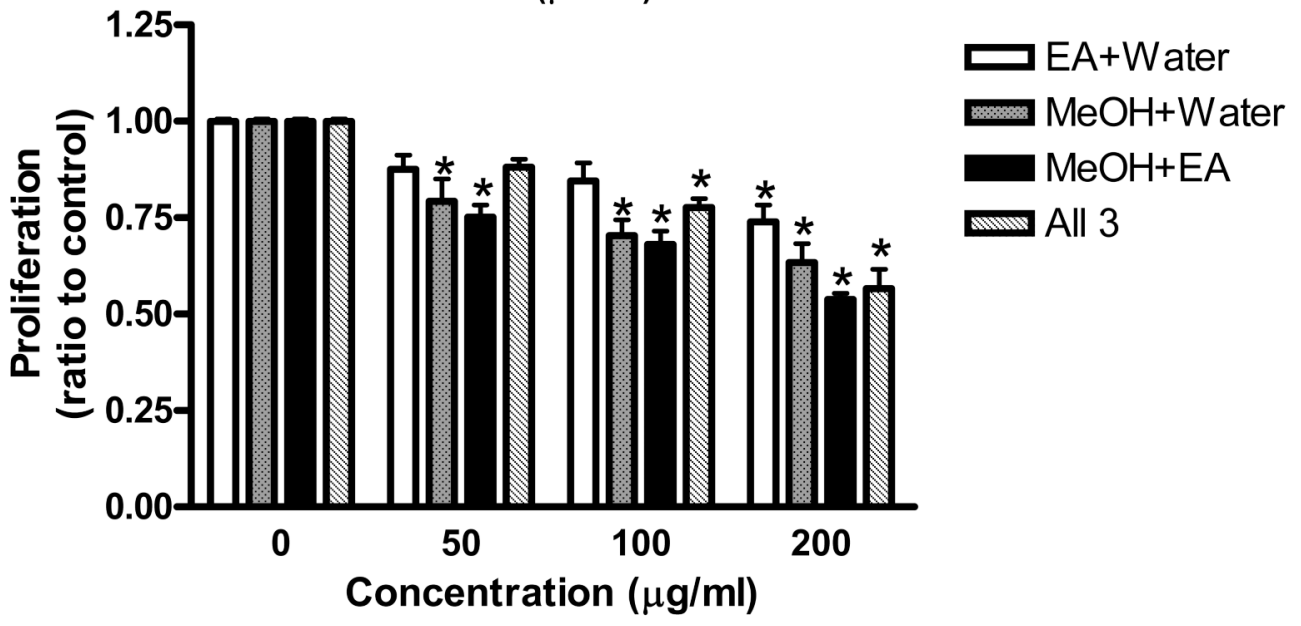

C

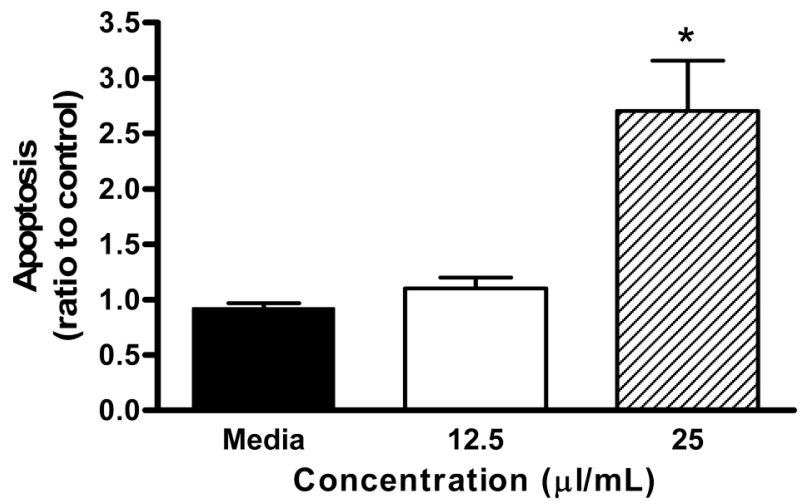

Figure 1. MDA-MB-231 cell proliferation and apoptosis

(A) Breast cell lines were treated with increasing concentrations of blueberry extract for 72 hours (B) MDA-MB-231 cells were treated with increasing concentrations of blueberry fractions (EA = ethyl acetate, $\mathrm{MeOH}=$ methanol, water fractions) for 72 hours. Proliferation was assessed using the CellTiter-Glo Luminescent Cell Viability Assay. Data are expressed as a ratio of treated samples to untreated controls, mean \pm SE. Asterisk indicates a significant difference $(n \geq 9, p \leq 0.01)$ compared to untreated controls. (C) Cells were exposed to blueberry extract at indicated concentrations for $72 \mathrm{~h}$, harvested and analyzed using the Cell Death

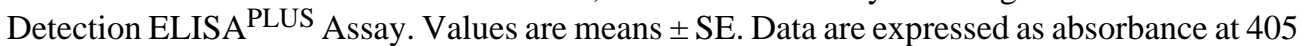


$\mathrm{nm}$ of each treated sample divided by control. Asterisk indicates a significant difference ( $\mathrm{n} \geq$ $12, \mathrm{p} \leq 0.01)$ compared to untreated controls. 
A

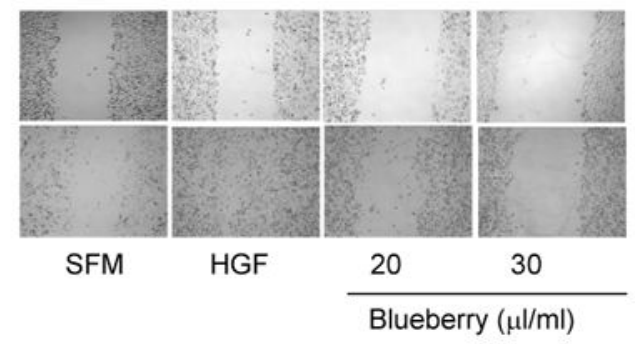

B

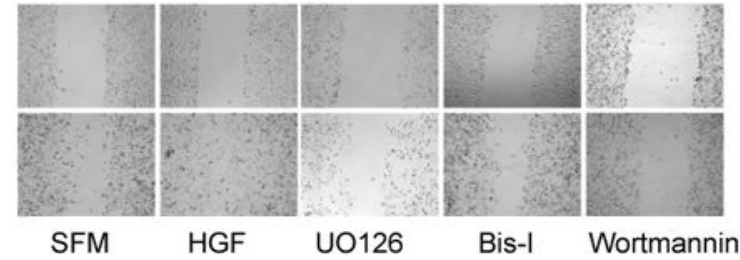

C
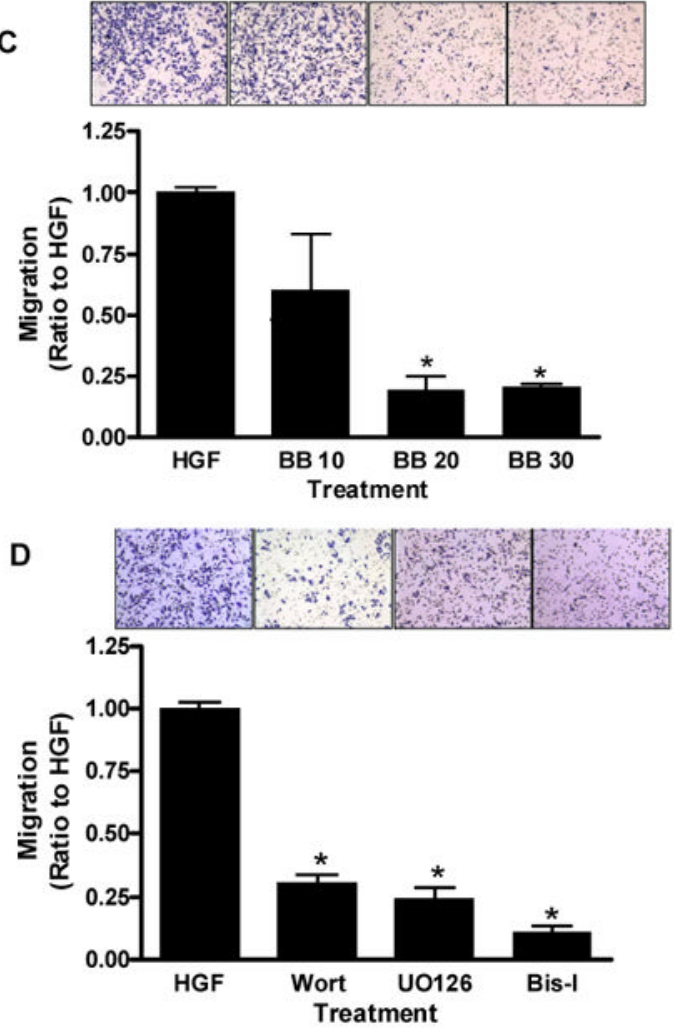

Figure 2. HGF-induced motility and migration in MDA-MB-231 cells

Confluent monolayers were scratched with a plastic pipette tip and incubated in serum free medium (SFM) in the presence of either HGF (40 ng/ml), or HGF plus blueberry (BB) extract (20 and $30 \mu \mathrm{l} / \mathrm{ml}$ ) (A) or various cell signaling inhibitors (B) for $24 \mathrm{~h}$. Migration of MDAMB-231 cells through a PET membrane (0.8 micron Transwell culture inserts) was evaluated in the presence or absence of blueberry (C) or various cell signaling inhibitors (D) after 24 hours of treatment. Quantification of the number of migrating cells from three separate experiments. Data is expressed as a ratio to HGF-treated cells; mean $\pm \mathrm{SEM}$. Asterisk indicates significant difference from HGF-treated cells $(\mathrm{n} \geq 3, \mathrm{p} \leq 0.01)$. 
A

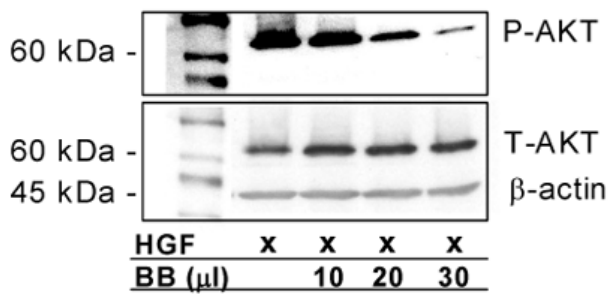

B

C
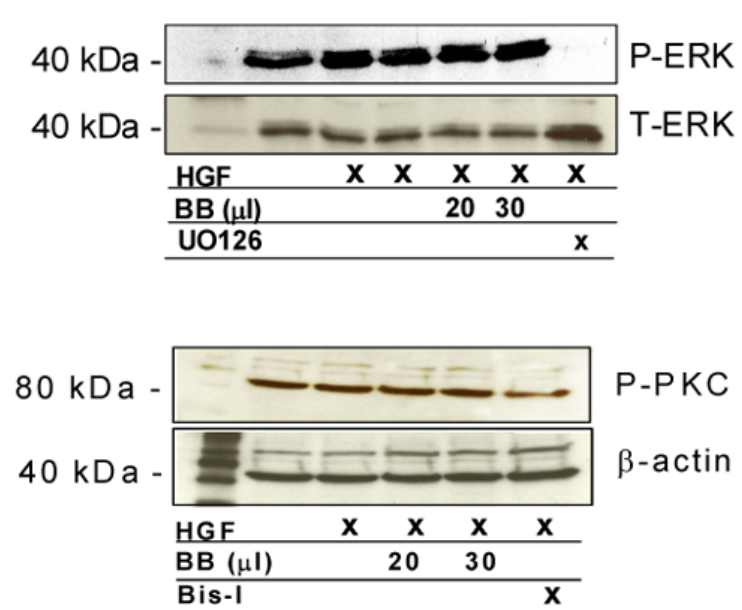

D

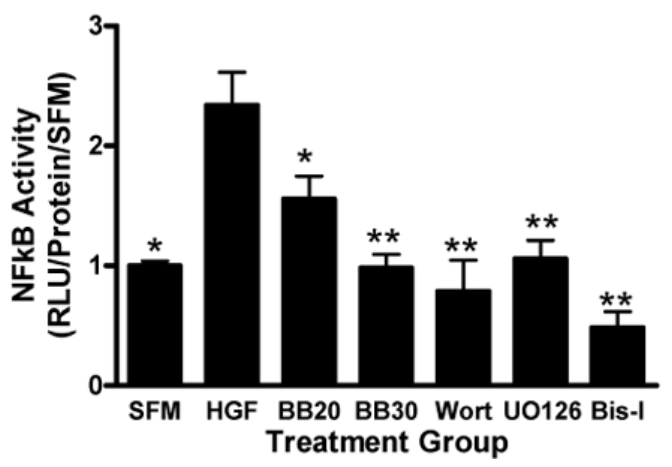

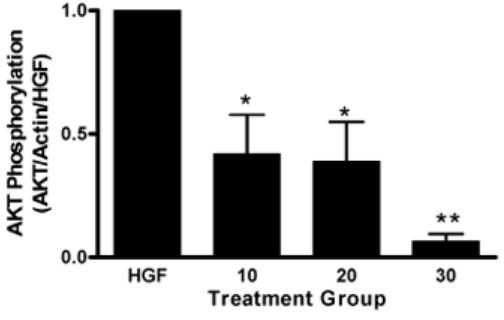
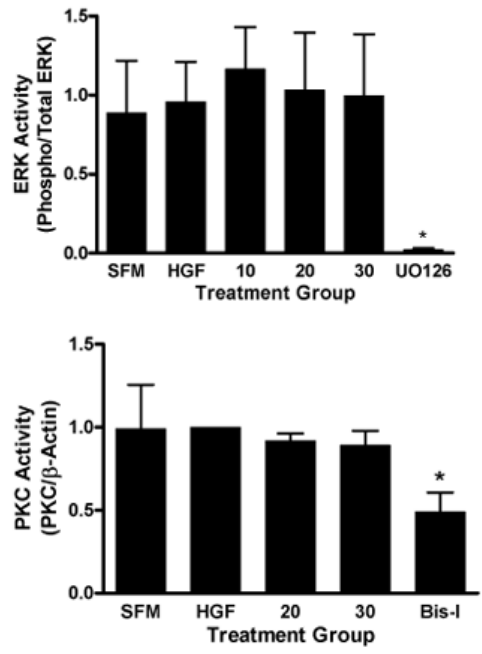

Figure 3. ERK, NFKB and AKT activation in MDA-MB-231 tumor cells

The phosphorylation of AKT (A), ERK (B) and PKC (C) in cell lysates from blueberry (BB), wortmannin (Wort), UO126 or Bis-I treated cells was determined via western blotting and chemiluninescence. Bar graphs indicate quantification of at least three separate blots using Quantity One software (Biorad). NFאB activity was evaluated via reporter gene assay (D). Luciferase activity was assayed after 24 hours and normalized to total protein. Data are expressed as relative luciferase units as a ratio of treated samples to serum free (SFM) samples. Values represent mean \pm SEM, asterisks indicate significant difference from HGF treated controls (single: $\mathrm{p} \leq 0.05$, double: $\mathrm{p} \leq 0.01$ ), $\mathrm{n} \geq 3$. 
A

B
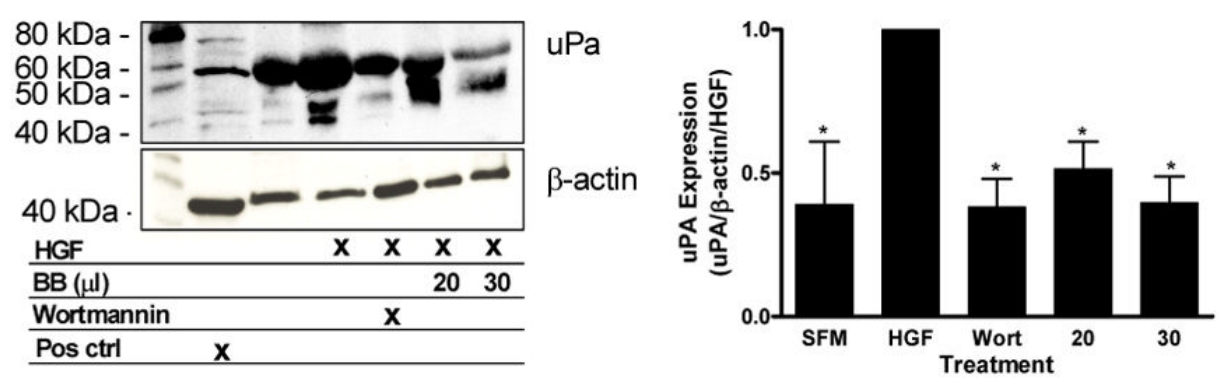

C
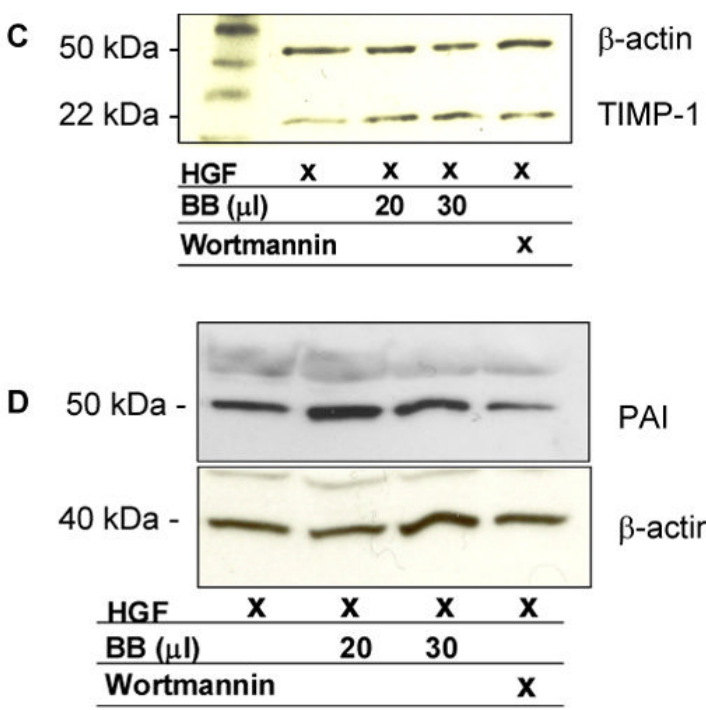

Figure 4. Modulation of metastatic proteins

(A) Inhibition of MMP-9 activity in conditioned medium from MDA-MB-231 cells treated with HGF (40 ng/ml) and blueberry (BB) extract $(20$ and $30 \mu \mathrm{l} / \mathrm{ml})$ or wortmannin (Wort) $(0.2$ $\mu \mathrm{M}$ ) for $24 \mathrm{~h}$ was evaluated via gelatin zymography. Bands were visualized on a Kodak Gel Logic 200 imaging system with the Kodak 1D software. Equal amounts of sample run on 10\% acrylamide gels and stained with coomassie blue as loading control. Conditioned medium from cells was evaluated for modulation of UPA (B), TIMP-1 (C) and PAI (D) secretion via western blotting and chemiluminescence. Bar graphs indicate quantification of at least three separate blots using Quantity One software (Biorad). Data represent mean in each group ( $\mathrm{n} \geq 3 \pm \mathrm{SEM}$ ). Asterisk indicates statistical significance from HGF-treated cells $(\mathrm{p} \leq 0.05)$. 
A

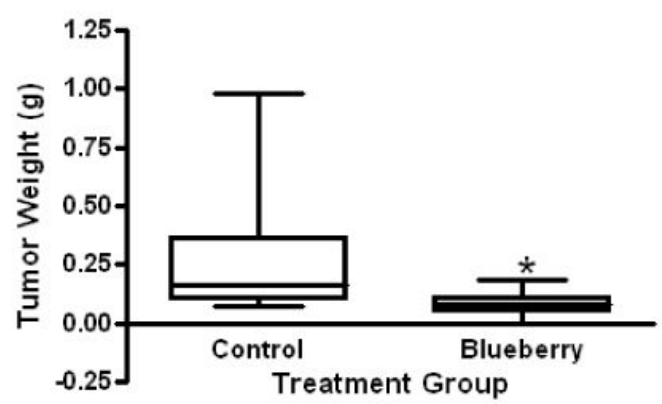

B
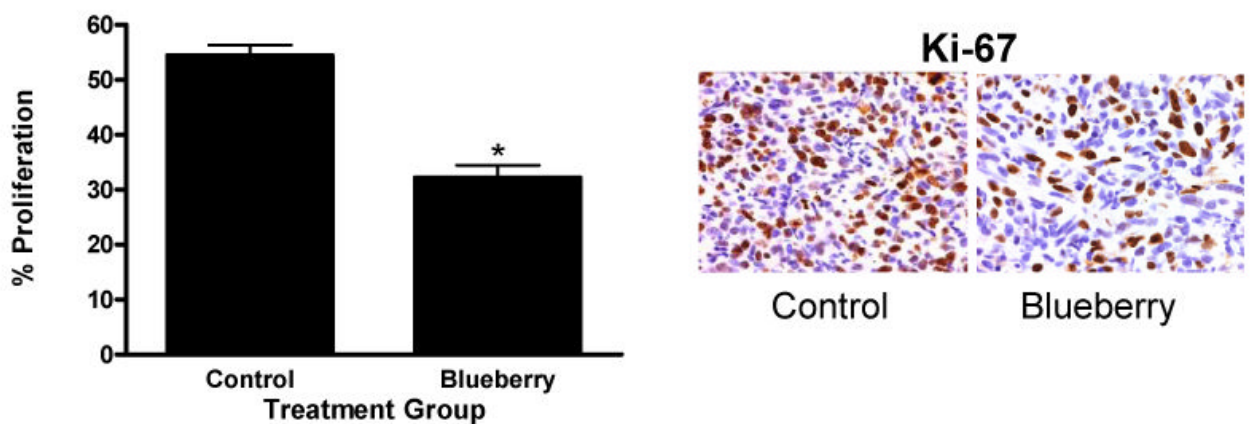

C
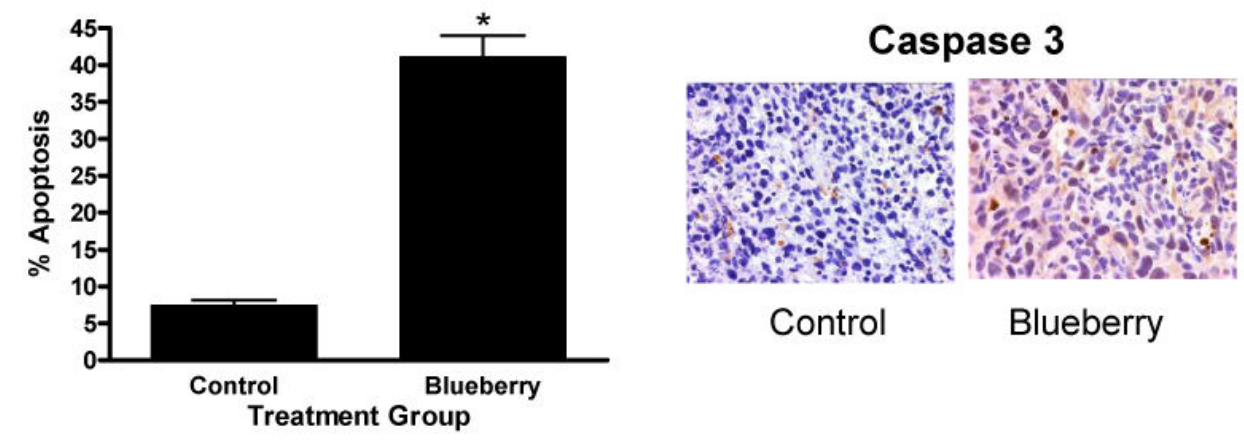

Figure 5. Inhibition of breast tumor growth

Seven to 8 -week-old athymic, nude female mice were gavage fed daily with $100 \mu \mathrm{l}$ blueberry extract or water. One week after the start of gavage, mice were s.c. injected in the right flank with MDA-MB-231 cells $\left(1 \times 10^{6}\right)$. After 6 weeks, mice were euthanized; tumors were removed, weighed and sent for histologic staining. Tumor weights are shown (A), Ki-67 antibody staining for cell proliferation (B), and cleaved caspase-3 for apoptosis (C) was evaluated via immunohistochemistry. Bar graphs indicate quantification of six random fields; stained and unstained cells were counted and divided by the total number of cells counted to generate the percentage of positive cells in each group. Data represent mean in each group ( $\mathrm{n} \geq 6 \pm S E M)$. Asterisk indicates statistical significance from control group, $(\mathrm{p} \leq 0.01)$. 

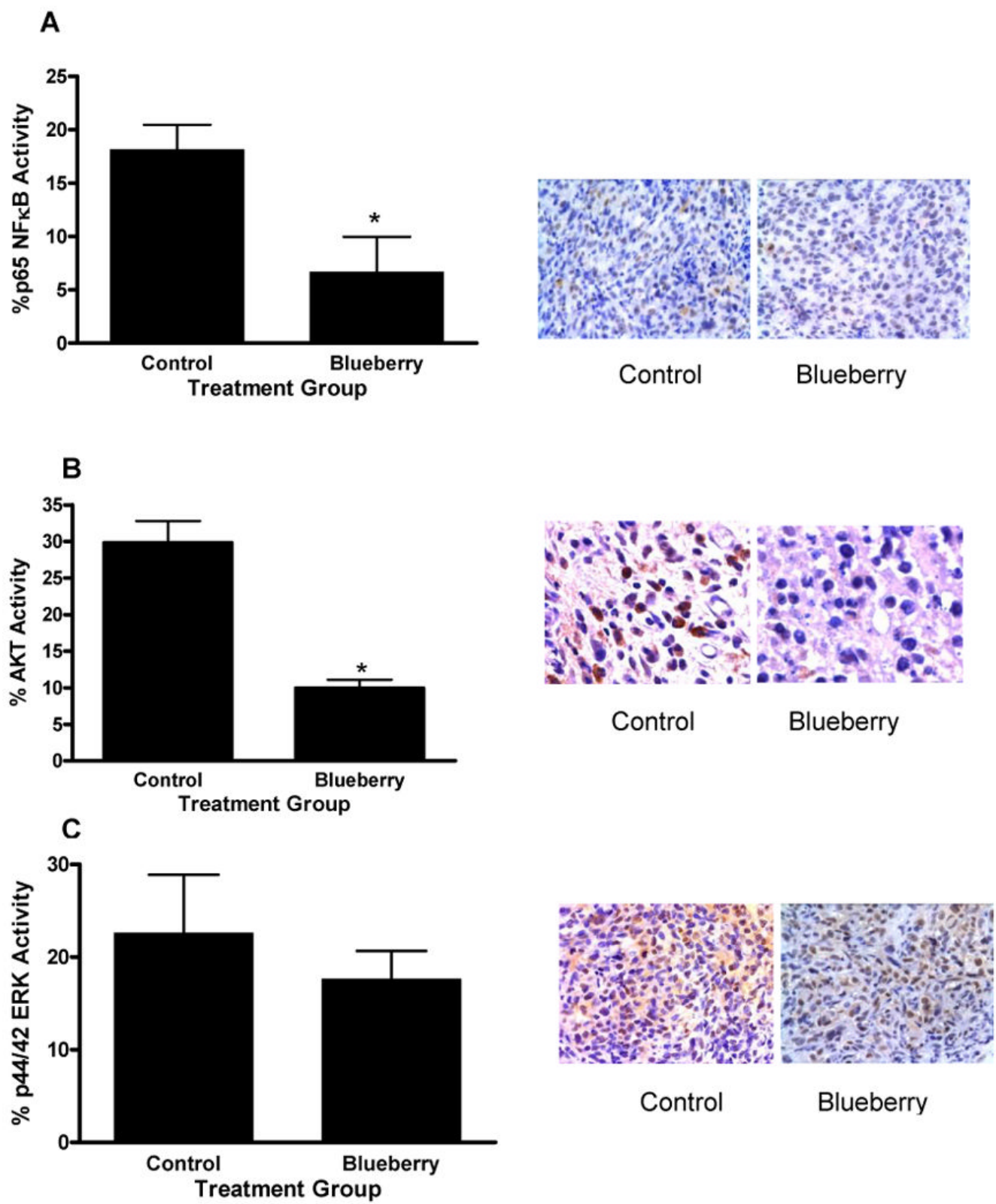

Control Blueberry

Figure 6. ERK, NFkB and AKT activation in MDA-MB-231 tumor xenografts Tumors from blueberry or water treated mice were antibody stained for phospho NFאB (A), AKT (B), or ERK (C) and evaluated via immunohistochemistry. Bar graphs indicate quantification of six random fields; stained and unstained cells were counted and divided by the total number of cells counted to generate the percentage of positive cells in each group. Data represent mean in each group $(\mathrm{n} \geq 6 \pm \mathrm{SEM})$. Asterisk indicates statistical significance from control group, $(\mathrm{p} \leq 0.01)$. 